\title{
BLAST FURNACE PROCESS IMPROVEMENT WITH PROBES AND MEASUREMENT SYSTEMS*
}

\author{
Jean-François Stumper ${ }^{1}$ \\ Mark Krüssmann ${ }^{1}$ \\ Claude Bodeving ${ }^{1}$ \\ Daniel Bastos Martins Cruz²
}

\begin{abstract}
In today's competitive steelmaking environment, the optimization and continuous supervision of the blast furnace process is of major importance. Modern probes and process measurement systems can assess the specific operation of the blast furnace. They provide a better and detailed process understanding and control. The benefits are even more important when they are combined with process models and expert systems. Everyday operation, productivity and even the lifetime of a blast furnace can be significantly improved by collecting, interpreting and acting upon such process data correctly. Only a comprehensive knowledge of the various process phenomena together with measurement of process variables inside the blast furnace enables the operators to optimize coke and fuel rates, to run the blast furnace smooth, reliable, and safe, and to make best use of the available raw materials. While the improvement of the blast furnace process with respect to productivity remains the main task, also, the timely identification of abnormalities and the assessment of process variations is an objective. This paper describes the blast furnace measurement systems that are available for everyday automatic use and provides an understanding for the possibilities of modern probes. The different applications are daily blast furnace supervision, charging process optimization, and observation of the internal state. Finally, the paper gives recommendations on probe configurations for different blast furnaces sizes, considering both a technical and an economical point of view.
\end{abstract}

Keywords: Blast furnace; Measuring systems; Process control.

1 TMT Tapping Measuring Technology, Luxembourg, Luxembourg; contact@tmt.com.

2 TMT Tapping Measuring Technology, Luxembourg; Paul Wurth do Brasil, Belo Horizonte, Brasil; pwbr@paulwurth.com.

\footnotetext{
* Technical contribution to the $44^{\text {th }}$ Ironmaking and Raw Materials Seminar, $15^{\text {rd }}$ Brazilian Symposium on Iron Ore and $2^{\text {nd }}$ Brazilian Symposium on Agglomeration of Iron Ore, September $15^{\text {th }}$ to $18^{\text {th }}$, 2014, Belo Horizonte, MG, Brazil.
} 


\section{INTRODUCTION}

It was only in the 1960s where engineers started to gain insight into the blast furnace process [1,2]. This has started with the dissection of blast furnaces and the detailed analysis of the internal state. These works made clear that there is a need for devices to measure process parameters such as the temperature, gas and burden.

Today, the extensive use of sensors along the blast furnace, such as skinflow systems to determine the temperature and pressure near the wall, pressure and temperature sensors in the uptakes, or a clean gas analyzer to determine the offgas composition, have become standard in most blast furnaces.

In addition to these measurements, more advanced measuring systems are required, in order to not only measure averaged values, but also the specific distribution of the temperature, the gas composition and the burden layers. Today, proven and reliable measurement systems are available to anyone via worldwide industrial suppliers. With these, the blast furnace process is made sufficiently transparent, such that a good operation practice and efficiency can be obtained.

This paper describes the probes that are commercially available today and that are suitable for everyday automatic use. The presentation is splitted into probes for everyday use that provide continuous measurements, and into probes for process optimization which provide measurements on demand. A suitable equipment recommendation is given at the end.

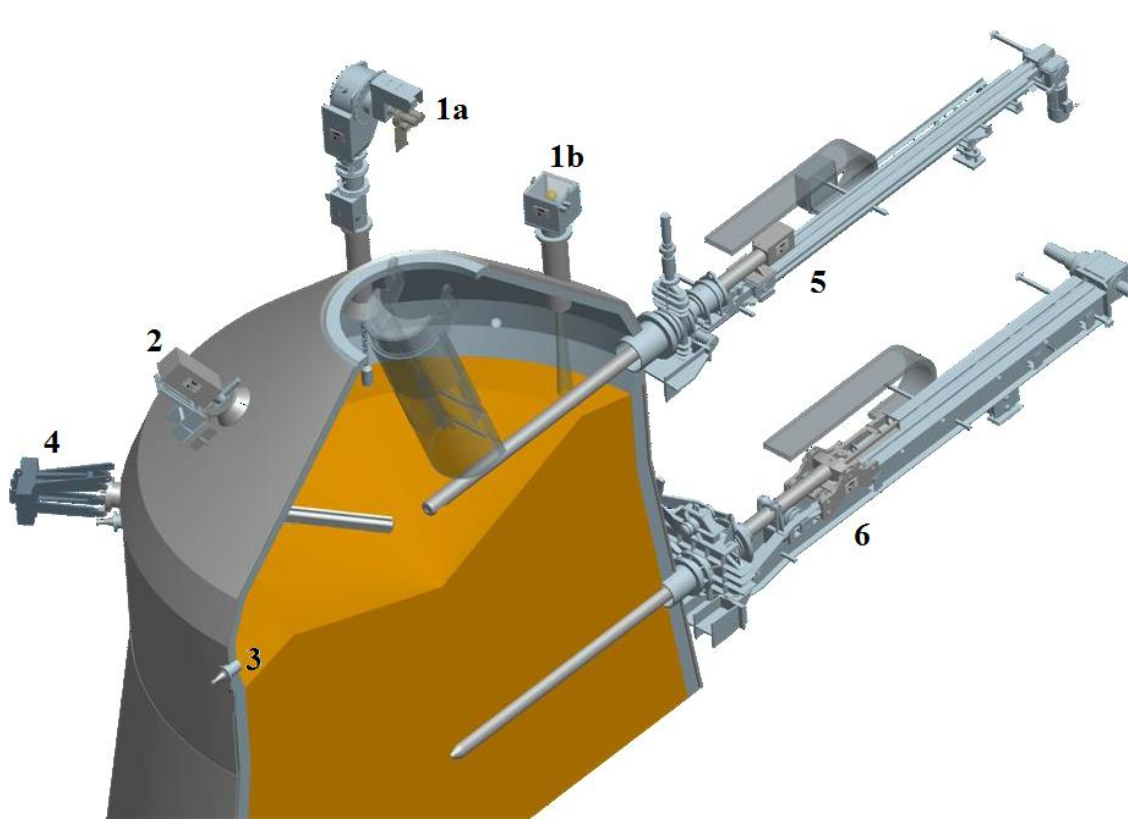

Figure 1. Blast furnace top equipped with probes

\author{
1 Mechanical and Radar \\ Stockline Detectors \\ Burden Level \\ 2 Furnoscope \\ 3 SOMA \\ 2D Top Gas Temperature \\ Distribution
}

4 Above-burden Gas and
Temperature Probe
Top Gas Temperature
and Gas distribution
5 Profilemeter
Burden Profile
(Impact probe is similar)
6 In-Burden Probe
Temperature and Gas
Distribution
(Scanning Probe is similar)

Additionally, a set of special measurement devices is available. These measurements are mainly for process R\&D, to gain deeper insight inside the blast furnace process. The most prominent system is the multi-point vertical probe (MPVP), which provides the gas and temperature distribution over the blast furnace cross section, from top to bottom [10]. This measurement is based on a consumable device, inserted via the Profilemeter carriage. Another such system is the tuyere probe. During stoppage, it can drill a material sample through the tuyere opening, in order to obtain material samples of the deadman to assess the coke particle size, permeability and material composition therein. The tuyere probe can also be

\footnotetext{
* Technical contribution to the $44^{\text {th }}$ Ironmaking and Raw Materials Seminar, $15^{\text {rd }}$ Brazilian Symposium on Iron Ore and $2^{\text {nd }}$ Brazilian Symposium on Agglomeration of Iron Ore, September $15^{\text {th }}$ to $18^{\text {th }}$, 2014, Belo Horizonte, MG, Brazil.
} 
combined with a special tuyere, in a way to insert and retract a lance right into the raceway during operation. This system can provide the temperature and samples of gas or material during blast furnace operation. These probes are, however, not further described in this paper.

\section{PROBES FOR EVERYDAY OPERATION}

\subsection{Acoustic Gas Temperature Measurement: TMT SOMATM}

The TMT SOMA ${ }^{\mathrm{TM}}$ system is an acoustic gas temperature measurement system that provides the two-dimensional top gas temperature distribution. Eight or more nitrogen-fed acoustic horns are installed around the blast furnace circumference, operating as acoustic transmitter and receiver. The physical principle is the relationship between the speed of sound and the gas temperature. With a combination of algorithms for signal processing and for tomography, the system can measure the absolute top gas temperature over the complete top cone area.

Acoustic waves can penetrate through the dusty and turbulent blast furnace atmosphere. Unlike an above-burden temperature probe, no mechanical components are situated inside the blast furnace and interfere with charging. All components are situated in a safe location outside the shell. The system therefore provides a reliable and continuous measurement with lowest possible maintenance.

The TMT SOMA ${ }^{\mathrm{TM}}$ system constitutes a recent development for blast furnace probes. A more detailed description is found in [3].

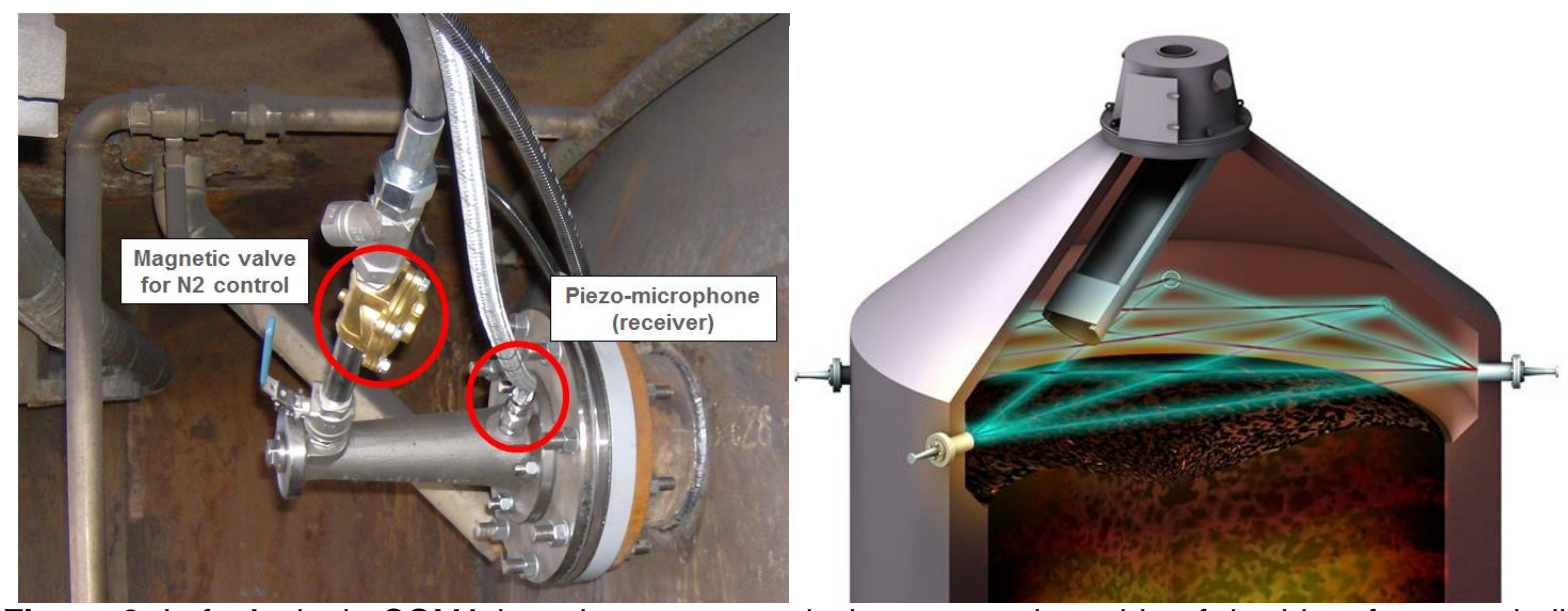

Figure 2. Left: A single SOMA horn is a compact device mounted outside of the blast furnace shell. Right: 8 such horns are installed around the circumference to measure the 2D top gas temperature at a defined level. For large blast furnaces, 10 or more horns can be used.

\footnotetext{
* Technical contribution to the $44^{\text {th }}$ Ironmaking and Raw Materials Seminar, $15^{\text {rd }}$ Brazilian Symposium on Iron Ore and $2^{\text {nd }}$ Brazilian Symposium on Agglomeration of Iron Ore, September $15^{\text {th }}$ to $18^{\text {th }}$, 2014, Belo Horizonte, MG, Brazil.
} 


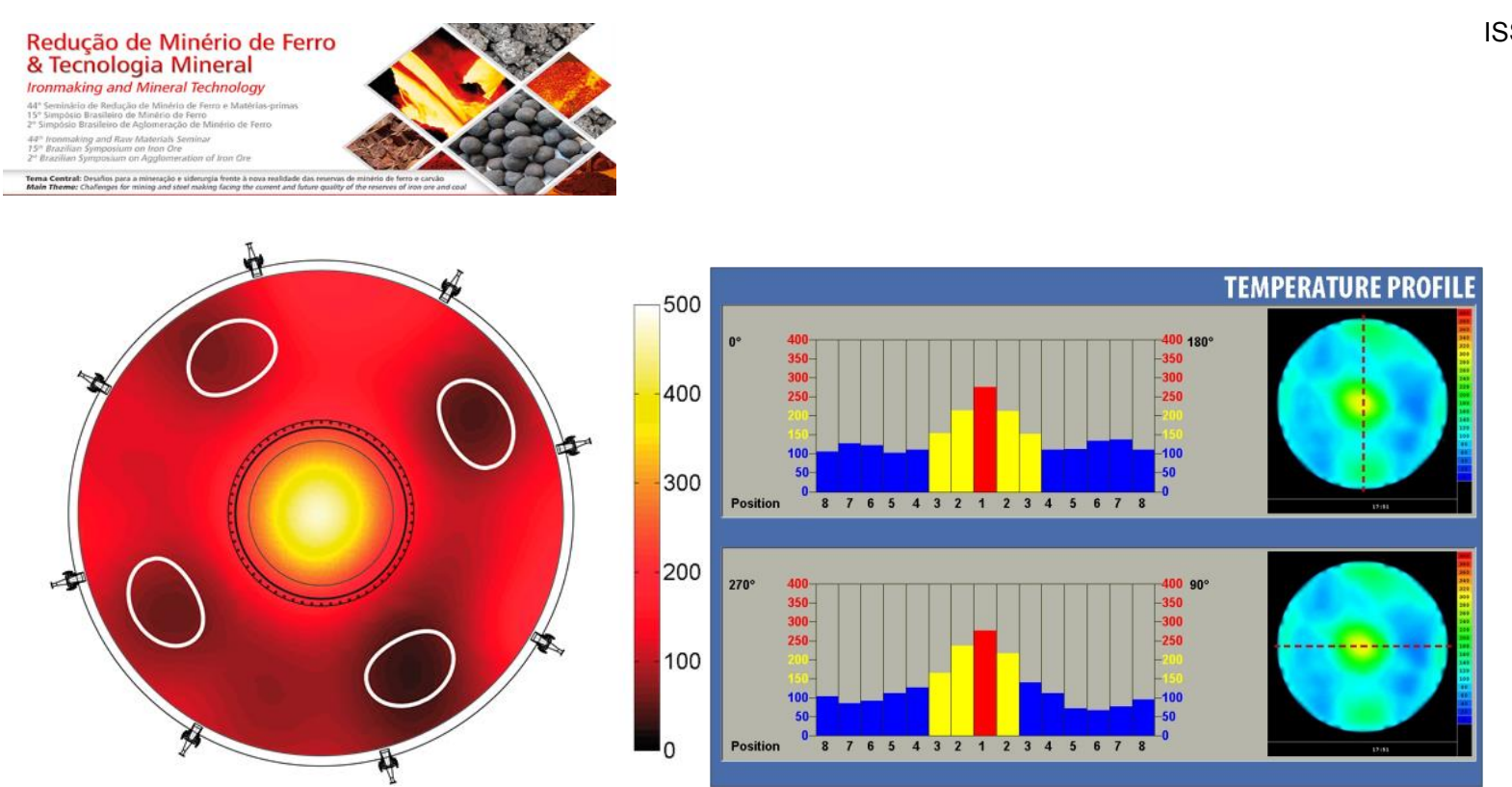

Figure 3. Left: The 2D temperature distribution shows the position and size of the central chimney, even the reduced temperature below the uptakes is seen. Right: Screenshot of the most common user interface. A virtual beam is introduced at a desired position, the bars display the temperature in the way operators are used to read conventional above-burden probes.

\subsection{Furnoscope: FS}

The TMT Furnoscope is a near-infrared camera, specifically adapted to the blast furnace requirements. Wide-angle lenses provide a view angle of $>130^{\circ}$ to visualize the complete burden surface and the armor. A special vortex nitrogen stream flushing prevents contamination of the optics. All this is embedded in a process-safe system including a number of safety functions, foremost a shutoff valve which automatically closes in case of any malfunction.

The camera provides thermal images, based on the infrared emission of the hot burden. The thermal emission is the only method to obtain optical images of the BF inside, as there is no light source inside the blast furnace. The TMT Furnoscope is therefore designed with high care regarding the light efficiency. Apart from state of the art camera and optics technology, an electromechanical light intensity control loop is integrated. While a minimum temperature is still physically required to obtain a bright image, the system can adapt itself to a very wide dynamic range of temperatures.

An infrared camera does not measure the gas temperature, but only the solid material emission. The actual top gas temperature cannot be measured. As such, it cannot replace a top gas temperature measurement system (like an above-burden temperature probe or TMT SOMA ${ }^{\mathrm{TM}}$ ). In practice, the central gas flow is seen because of the dust content.

The TMT Furnoscope provides real time video view inside the operating blast furnace. Blast furnace operators can verify proper operation on a simple video screen. Furthermore, information on the temperature distribution of the burden is obtained to verify the burden drying process. Process abnormalities, such as a noncentral gas flow, gas flow channeling, or a rapid temperature increase, can be detected in order to take protective measures such as, for instance, top cone water or steam injection.

\footnotetext{
* Technical contribution to the 44 Ironmaking and Raw Materials Seminar, $15^{\text {rd }}$ Brazilian Symposium on Iron Ore and $2^{\text {nd }}$ Brazilian Symposium on Agglomeration of Iron Ore, September $15^{\text {th }}$ to $18^{\text {th }}$, 2014, Belo Horizonte, MG, Brazil.
} 

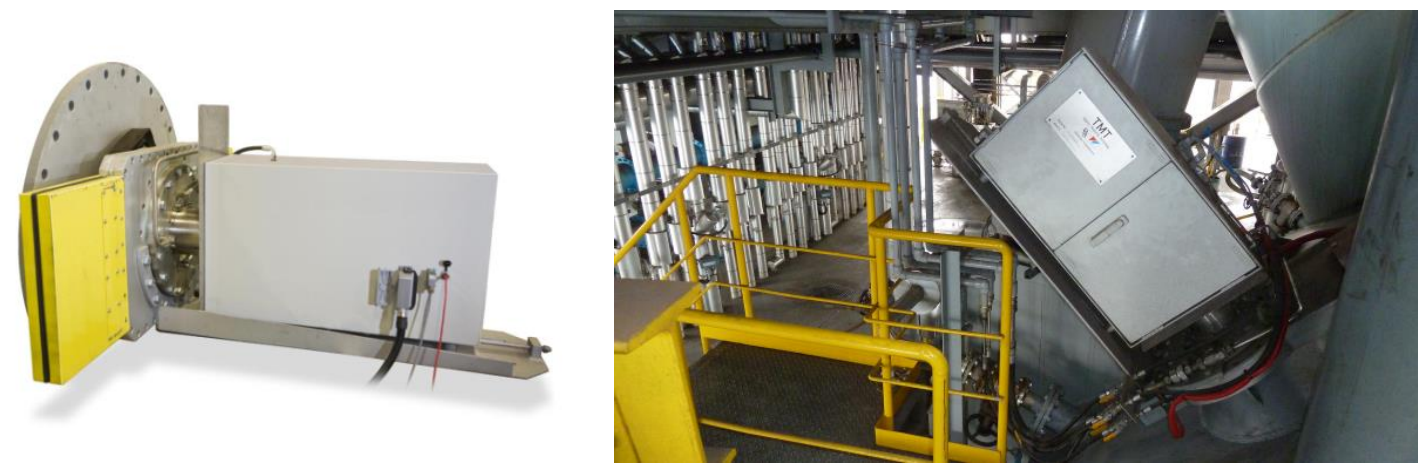

Figure 4. Left: Furnoscope with compact shutoff valve. Right: Furnoscope installed on a BF top cone.
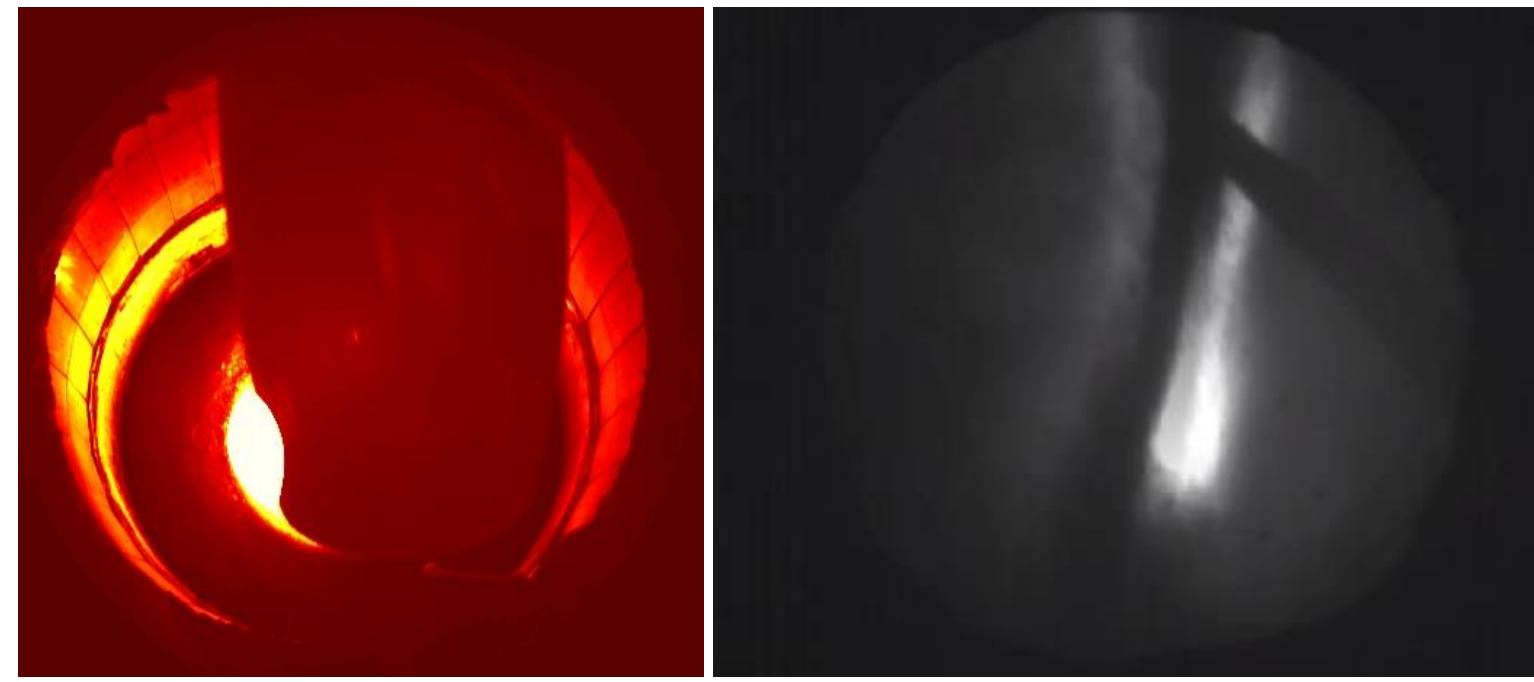

Figure 5. Furnoscope results. Left: during stoppage, a very clear image appears as there is no dust, and the armor, the mechanical stockrod, and the chute are recognized. Right: during charging, a lot of dust appears, but still, the material stream, the central gas flow and the temperature beam are visible.

\subsection{Mechanical Stockline Probe: SLM}

The mechanical stockline probe is a burden level measurement, based on lowering a weight on the burden via a chain. At least one such device is present in almost all blast furnaces. Today, it serves foremost as a backup measurement, providing the filling level reliably even in though operation conditions, or during top cone water or steam injection.

As the TMT probe comes with a shutoff valve and a well-elaborated design, all maintenance, including recalibration and replacement of the weight, can be done during operation of the blast furnace.

\footnotetext{
* Technical contribution to the 44 Ironmaking and Raw Materials Seminar, $15^{\text {rd }}$ Brazilian Symposium on Iron Ore and $2^{\text {nd }}$ Brazilian Symposium on Agglomeration of Iron Ore, September $15^{\text {th }}$ to $18^{\text {th }}$, 2014, Belo Horizonte, MG, Brazil.
} 


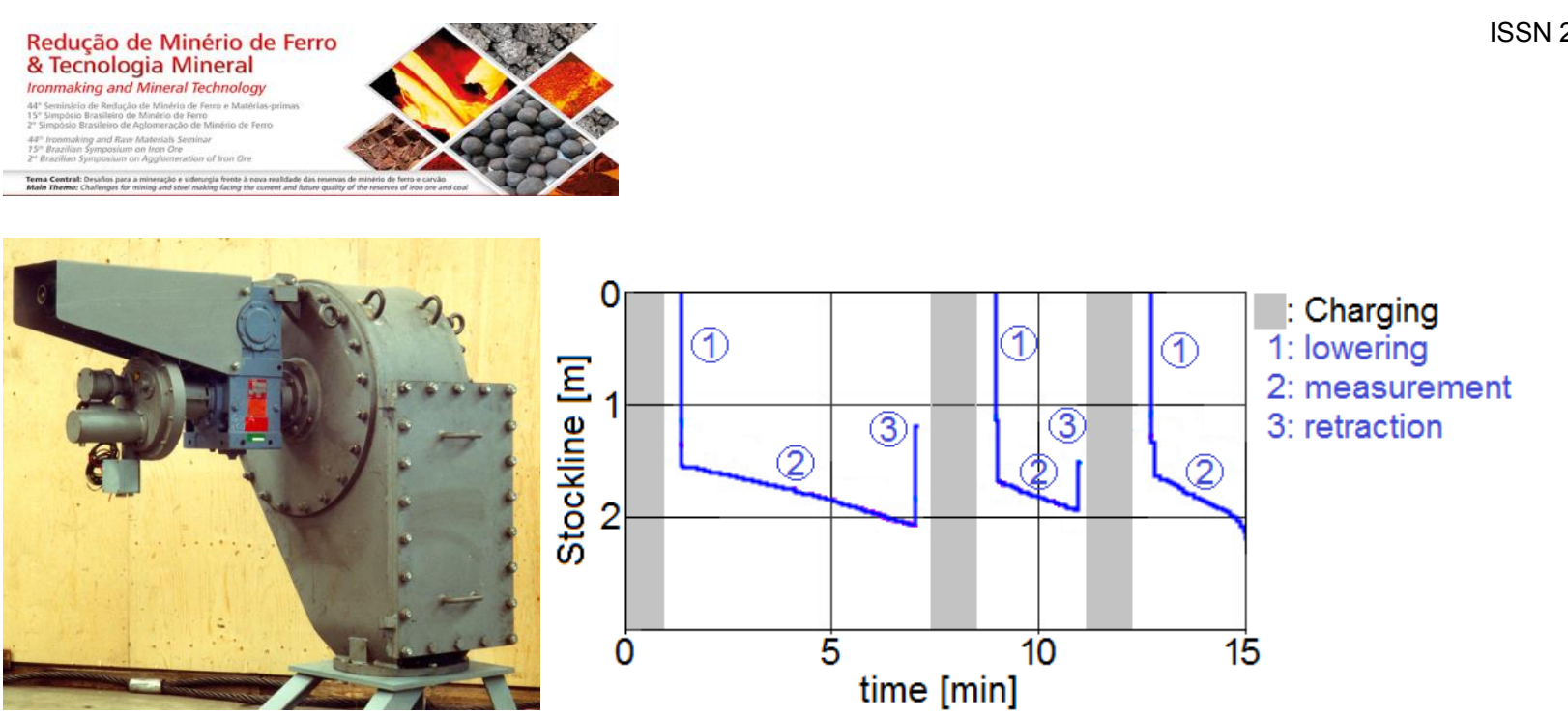

Figure 6. Left: The top part of SLM is the housing for the chain winch, the electric motor and encoder, and the opening plate for weight maintenance. Right: The measurement consists of the weight lowering after charging, tracking the burden level descent, and retracting the weight before charging.

\subsection{Stockline Radar: SLR}

A stockline radar is a burden level measurement system. It is the modern equivalent of a mechanical stockline rod, convincing with its lower maintenance requirements and the ability to measure continuously even during charging, thus providing a higher catchup rate for charging. Additionally, today's probes are designed to be fully accessible for maintenance even during operation.

Radar technology is based on electromagnetic waves, comparable to radio waves. The choice for this technology is supported by several features. The radar waves propagate at the speed of light and are therefore independent of the temperature or the gas composition. The radar waves have a wavelength of several millimeters and can penetrate through the dusty and turbulent blast furnace atmosphere.

TMT provides radar devices since the early 90s and has a vast experience in the application to blast furnaces, which have quite specific requirements. The materials are of considerably different grain sizes and electrical characteristics, and the dusty and turbulent atmosphere requires adequate signal processing.

The main use for a SLR is the burden level measurement for charging control. By defining a 'stockline calling level', the charging is automatically triggered once the burden level is below this threshold.

A measurement that became popular only recently is the centerline radar. Here, the level of the most central point of the burden surface is continuously monitored. A radar is installed under $45^{\circ}$ to point to the center. This provides important data regarding center coke charging, for instance. In this charging method, ore layers should only be placed at the radius but not at the center, in order that a central coke chimney forms. A well operating radar can continuously supervise that during ore charging, the BF center level is not influenced.

\footnotetext{
* Technical contribution to the 44 Ironmaking and Raw Materials Seminar, $15^{\text {rd }}$ Brazilian Symposium on Iron Ore and $2^{\text {nd }}$ Brazilian Symposium on Agglomeration of Iron Ore, September $15^{\text {th }}$ to $18^{\text {th }}$, 2014, Belo Horizonte, MG, Brazil.
} 

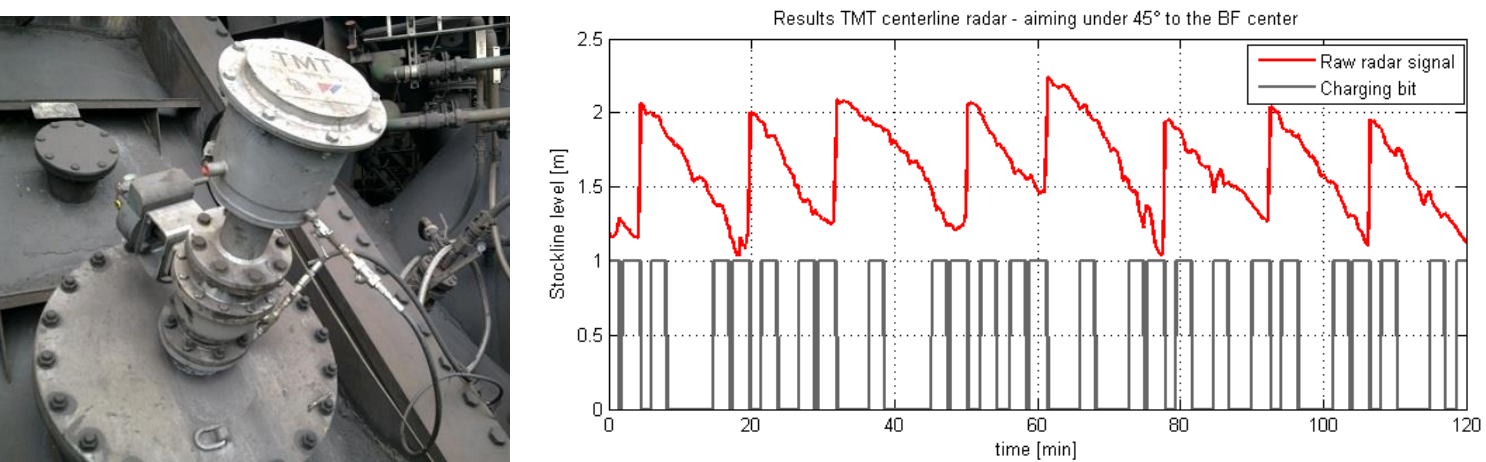

Figure 7. Left: TMT SLR with ball valve and gastight encasing for high reliability. Right: measurement result of a centerline radar aiming under $45^{\circ}$ inclination to the BF center. It can be observed that the signal can remain steady even during charging.

\section{PROBES FOR PROCESS CONTROL AND OPTIMIZATION}

The blast furnace is a counter-current reactor, characterized by the descending raw materials and the ascending process gas. The actual reduction process from iron ores to raw iron happens by chemical reactions between a reducing gas (i.e., CO) and a solid (i.e., Fe2O3). The gas flow distribution in the blast furnace is controlled with the burden distribution [6-8]. The gas flow distribution is the key parameter to influence the blast furnace performance [1].

\begin{tabular}{|c|c|c|c|c|c|c|c|c|c|c|c|c|c|c|c|c|c|c|c|c|c|c|c|c|c|c|c|c|c|c|c|}
\hline & $\begin{array}{l}\text { Primary } \\
\text { Material }\end{array}$ & $\begin{array}{l}\text { Weight } \\
\text { [kg] }\end{array}$ & $\begin{array}{l}\text { Volume } \\
\text { [mi] }\end{array}$ & $\begin{array}{c}\text { Time } \\
{[s]}\end{array}$ & $\begin{array}{l}\text { Flow } \\
{[\mathrm{mi} / \mathrm{s}]}\end{array}$ & End & R11 & & R10 & & R9 & & R8 & & $\mathrm{R} 7$ & & R6 & & R5 & & R4 & & R3 & & R2 & & R1 & & $\begin{array}{c}\text { Use } \\
\text { Batch } \\
\text { Charge } \\
\text { Level }\end{array}$ & $\begin{array}{l}\text { Batch } \\
\text { Charge } \\
\text { Level } \\
\text { [mm] }\end{array}$ & $\begin{array}{c}\text { Tilt } \\
\text { Direction }\end{array}$ \\
\hline 1 & $\mathrm{CY} 1$ & 20300 & 41.4 & 90.0 & 0.46 & $\Gamma$ & 0 & $\Gamma$ & 0 & $\Gamma$ & 2 & $\Gamma$ & 1 & $\Gamma$ & 1 & $\Gamma$ & 1 & $\Gamma$ & 1 & $\Gamma$ & 1 & $\Gamma$ & 2 & $\Gamma$ & 1 & $\Gamma$ & 2 & $\Gamma$ & $\nabla$ & 1500 & $W \cdot>C$ \\
\hline 2 & $\mathrm{S13}$ & 84500 & 49.8 & 82.5 & 0.60 & $\Gamma$ & $\mathbf{0}$ & $\Gamma$ & 1 & $\Gamma$ & 1 & $\Gamma$ & 1 & $\Gamma$ & 2 & $\Gamma$ & 1 & $\Gamma$ & 2 & $\Gamma$ & 1 & $\Gamma$ & 1 & $\Gamma$ & 1 & $\Gamma$ & $\mathbf{0}$ & $\Gamma$ & $\nabla$ & 1500 & $W \cdot>C$ \\
\hline 3 & $\mathrm{CY} 1$ & 20300 & 41.4 & 90.0 & 0.46 & $\Gamma$ & $\mathbf{0}$ & $\Gamma$ & 0 & $\Gamma$ & 1 & $\Gamma$ & 2 & $\Gamma$ & 2 & $\Gamma$ & 1 「 & $\Gamma$ & $1 \Gamma$ & $\Gamma$ & 1 & $\Gamma$ & 1 & $\Gamma$ & 1 & $\Gamma$ & 2 & $\Gamma$ & $\nabla$ & 1500 & $W \cdot>C$ \\
\hline 4 & $\$ 13$ & 84000 & 48.8 & 90.0 & 0.54 & $\Gamma$ & 0 & $\Gamma$ & o & $\Gamma$ & 2 & $\Gamma$ & 1 & $\Gamma$ & 2 & $\Gamma$ & 2 & $\Gamma$ & $1 \Gamma$ & $\Gamma$ & 2 & $\Gamma$ & 2 & $\Gamma$ & $\mathbf{0}$ & $\Gamma$ & $\mathbf{0}$ & $\Gamma$ & $\nabla$ & 1500 & $W \cdot>C$ \\
\hline 5 & $\mathrm{CY} 1$ & 20300 & 41.4 & 97.5 & 0.42 & $\Gamma$ & $\mathbf{0}$ & $\Gamma$ & 0 & $\Gamma$ & 2 & $\Gamma$ & 1 & $\Gamma$ & 1 & $\Gamma$ & 2 「 & $\Gamma$ & $1 \Gamma$ & $\Gamma$ & 2 & $\Gamma$ & 1 & $\Gamma$ & 1 & $\Gamma$ & 2 & $\Gamma$ & $\nabla$ & 1500 & $W \cdot>C$ \\
\hline 6 & 513 & 84500 & 49.8 & 82.5 & 0.60 & $\Gamma$ & $\mathbf{0}$ & $\Gamma$ & 1 & $\Gamma$ & 1 & $\Gamma$ & 1 & $\Gamma$ & 1 & $\Gamma$ & $1 \Gamma$ & $\Gamma$ & $2 \Gamma$ & $\Gamma$ & 2 & $\Gamma$ & 2 & $\Gamma$ & $\mathbf{0}$ & $\Gamma$ & $\mathbf{0}$ & $\Gamma$ & $\sqrt{\nabla}$ & 1500 & $W \cdot>C$ \\
\hline 7 & $\mathrm{CY} 1$ & 20300 & 41.4 & 90.0 & 0.46 & $\Gamma$ & 0 & $\Gamma$ & 0 & $\Gamma$ & 1 & $\Gamma$ & 1 & $\Gamma$ & 1 & $\Gamma$ & 2 & $\Gamma$ & $1 \Gamma$ & $\Gamma$ & 1 & $\Gamma$ & 1 & $\Gamma$ & 1 & $\Gamma$ & 3 & $\Gamma$ & $\nabla$ & 1500 & $W \cdot>C$ \\
\hline 8 & 513 & 84000 & 48.8 & 82.5 & 0.59 & $\nabla$ & $\mathbf{0}$ & $\Gamma$ & 0 & $\Gamma$ & 1 & $\Gamma$ & 2 & & 1 & $\Gamma$ & $1 \Gamma$ & $\Gamma$ & $2 \Gamma$ & $\Gamma$ & 1 & $\Gamma$ & 1 & $\Gamma$ & 2 & $\Gamma$ & 0 & $\Gamma$ & $\nabla$ & 1500 & $W \cdot>C$ \\
\hline
\end{tabular}

Figure 8. A charging matrix is the control input for the burden distribution. The operators work with abstractions such as the eleven 'rings', the planned charging can be simulated using the 'Paul Wurth Charging Model'. The real output has to be verified with probes because of the strong dependency on process parameters.

Blast furnace probes can be used for supervising the burden distribution, to verify the overall process and to monitor the internal state. The measurements can be processed directly to models to obtain the data required for everyday operation. Furthermore, advanced models can be used for research purposes, for instance, to calculate the detailed gas flow pattern [2], or to estimate the shape and size of the cohesive zone [9,2], etc.

\subsection{Profilemeter: PM}

A Profilemeter is a movable probe installed above the burden to measure the radial surface profile between the charging sequences. After completion of the charging, the Profilemeter moves over the complete radius of the blast furnace. During this movement, a high-speed, high-precision radar device measures the vertical distance between the probe head and the burden surface. The combination of the horizontal position of the probe and the vertical distance to the burden gives the surface profile.

\footnotetext{
* Technical contribution to the 44 Ironmaking and Raw Materials Seminar, $15^{\text {td }}$ Brazilian Symposium on Iron Ore and $2^{\text {nd }}$ Brazilian Symposium on Agglomeration of Iron Ore, September $15^{\text {th }}$ to $18^{\text {th }}$, 2014, Belo Horizonte, MG, Brazil.
} 
To increase reliability, the profilemeter is designed such that no electronic components are inserted into the blast furnace. Indeed, all radar electronics are situated outside of the blast furnace in the open atmosphere. The radar waves are guided via a specially designed waveguide and antenna system to the probe tip. The reasons for using radar technology are identical to those explained in the SLR section. The typical utilization frequency of the Profilemeter is once per shift (i.e., once every 8 hours).

The profiles can be either recorded and visualized one by one, or processed into a layer model. The layer model is the major process model resulting from this probe. It represents the burden profiles that were measured one after the other, together with the charged volumes. The layer model indicates the shape of the layers in the blast furnace. The layer model ignores, however, the effects of coke pushing, percolation, and coke fluidization.

Based on the layer model, the $\mathrm{C} /(\mathrm{C}+\mathrm{O})$ ratio is calculated. This radial burden distribution indicates the permeability and the gas distribution in the blast furnace.

By comparing the measurements obtained over a given time interval (i.e., a number of weeks), the stability of the charging and of the blast furnace process can be verified. The influence of specific process parameter changes can be identified: wear of the BLT chute, a change of raw burden material, a change in material screening or a change in conveyor belt charging sequence, etc.

It is also possible to measure the radial distribution of the burden descent speed. Two profiles are recorded within a time interval of several minutes, but without an intermittend charging. The burden descent speed has to be supervised regularly for flat profile charging.
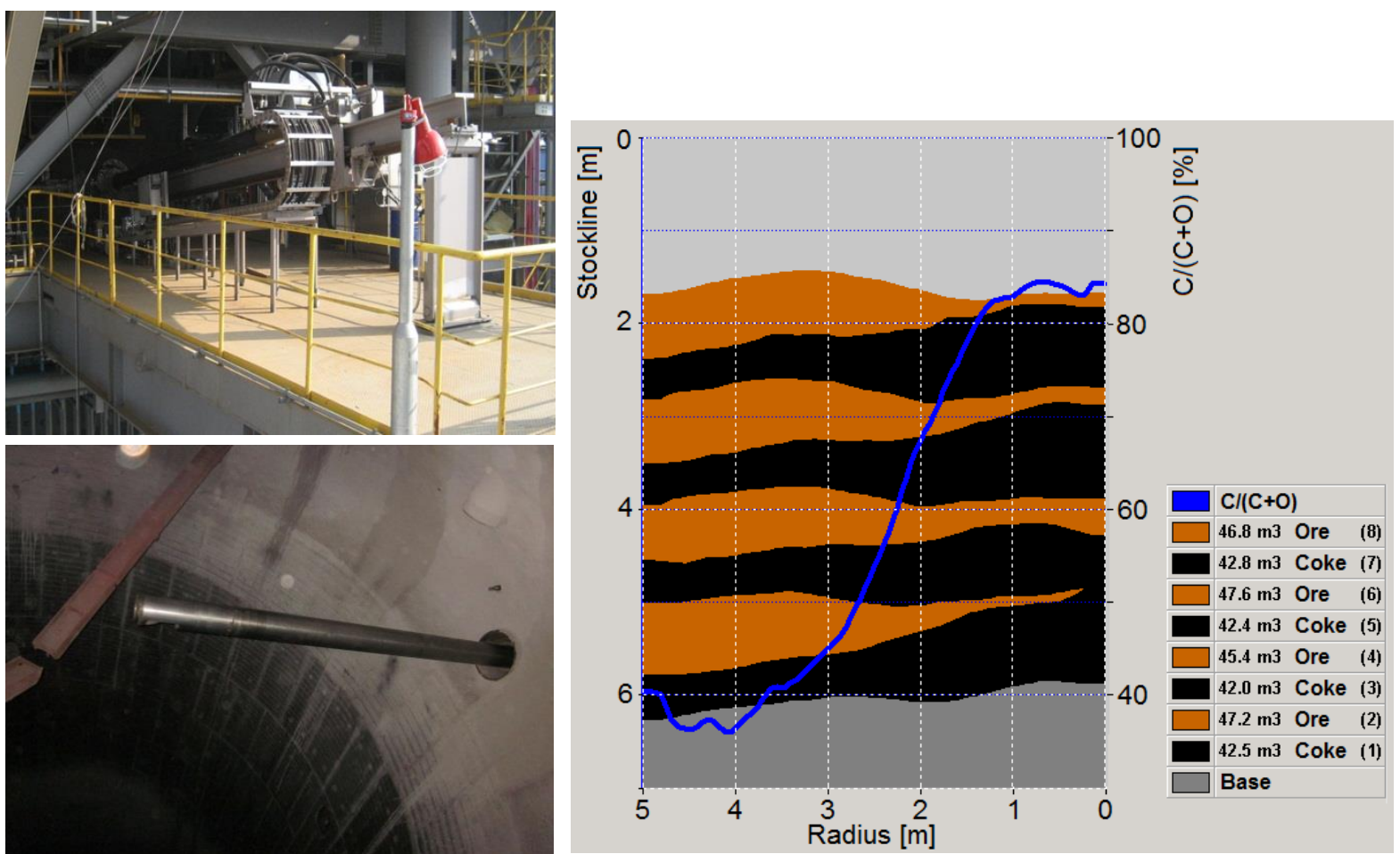

Figure 9. Left: TMT Profilemeter. External view and movement inside the blast furnace. Right: A layer model is the regular measurement result. Such a model visualizes the recorded burden surface profiles and the charged volumes.

\footnotetext{
* Technical contribution to the 44 Ironmaking and Raw Materials Seminar, $15^{\text {td }}$ Brazilian Symposium on Iron Ore and $2^{\text {nd }}$ Brazilian Symposium on Agglomeration of Iron Ore, September $15^{\text {th }}$ to $18^{\text {th }}$, 2014, Belo Horizonte, MG, Brazil.
} 


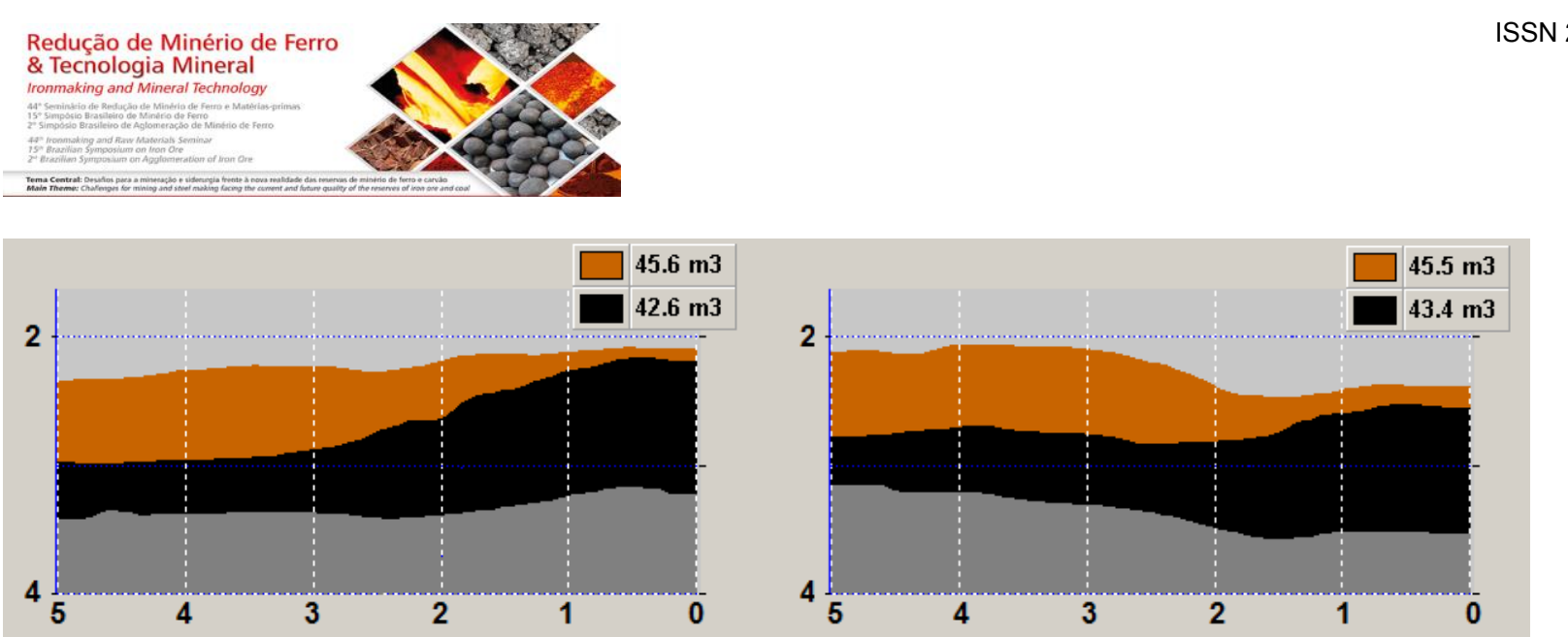

Figure 10. Flat-profile charging. Left: A regular layer structure where only coke will be in the center. The ore profile is flat and the coke profile is inclined. Right: Abnormal "inverted" layers where the coke profile is flat, and instead, the ore profile is inclined. Here, ore could move to the center. This situation can be prevented by a regular use of the Profilemeter.

\subsection{Impact Probe: IP}

The material falling curve from the rotating chute depends on many parameters, including the raw material properties (grain size, density) and the mechanical chute surface properties (including the stone box design and its abrasion). Usually, a preconfiguration of the rotating chute angle is done during its first installation. Engineers divide the blast furnace radius into 11 rings, each ring describing a section of the radius. Based on commissioning measurements, each ring is associated to a tilting angle of the chute. When designing the charging pattern (charging matrix), blast furnace operators will only work with the rings in order to avoid detailed calculations.

An Impact Probe is a movable probe installed above the burden, mechanically similar to the profilemeter. During charging, this probe sits in the stream of falling material. A series of sensors aligned on the probe detect the exact position of the falling material during operation. This data serves to calculate the material falling curves and, hence, the final position of the material on the surface.

With the impact probe, operators can verify the proper association of chute angles to the rings, and readjust the chute angles regularly. Experience shows that the chute abrasion over the lifetime leads to a deviation of up to $4^{\circ}$ of the tilting angle, thereafter affecting the burden distribution. Also, a change of raw material, of material granulometry, or a change in the sieving / loading procedure, will affect the falling curves.

An impact probe can be delivered as dedicated probe. It is also possible to combine the impact function with a Profilemeter, resulting in a cost-efficient system. The utilization frequency widely varies, from monthly to once per shift. For intense use, installing a dedicated probe is recommended.

\footnotetext{
* Technical contribution to the 44 Ironmaking and Raw Materials Seminar, $15^{\text {rd }}$ Brazilian Symposium on Iron Ore and $2^{\text {nd }}$ Brazilian Symposium on Agglomeration of Iron Ore, September $15^{\text {th }}$ to $18^{\text {th }}$, 2014, Belo Horizonte, MG, Brazil.
} 


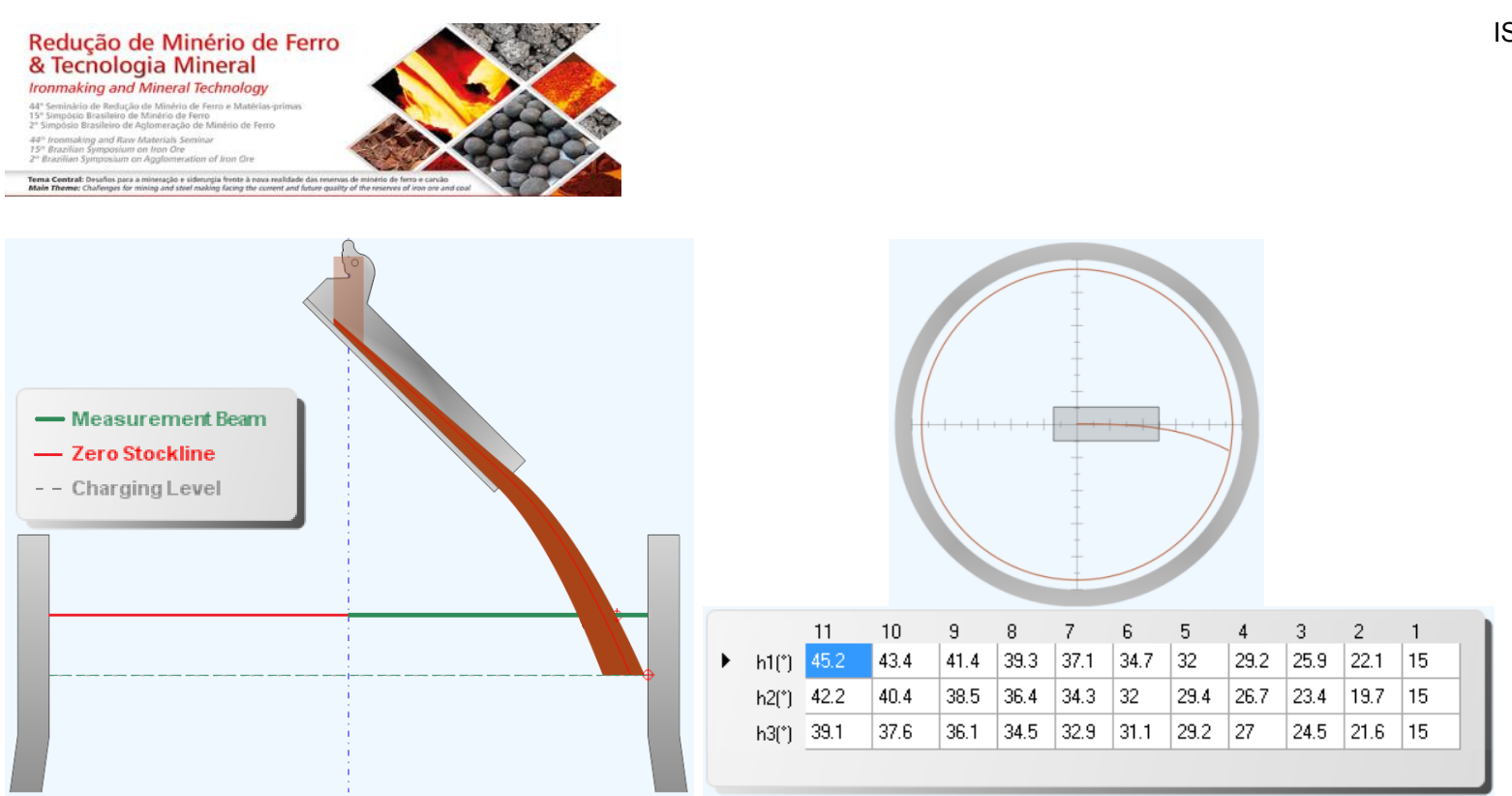

Figure 11. Left: Material stream and definition of falling curves. Right: Assignment of Ring definition to a tilting angle is also depending on the material (i.e., either coke or sinter iron).

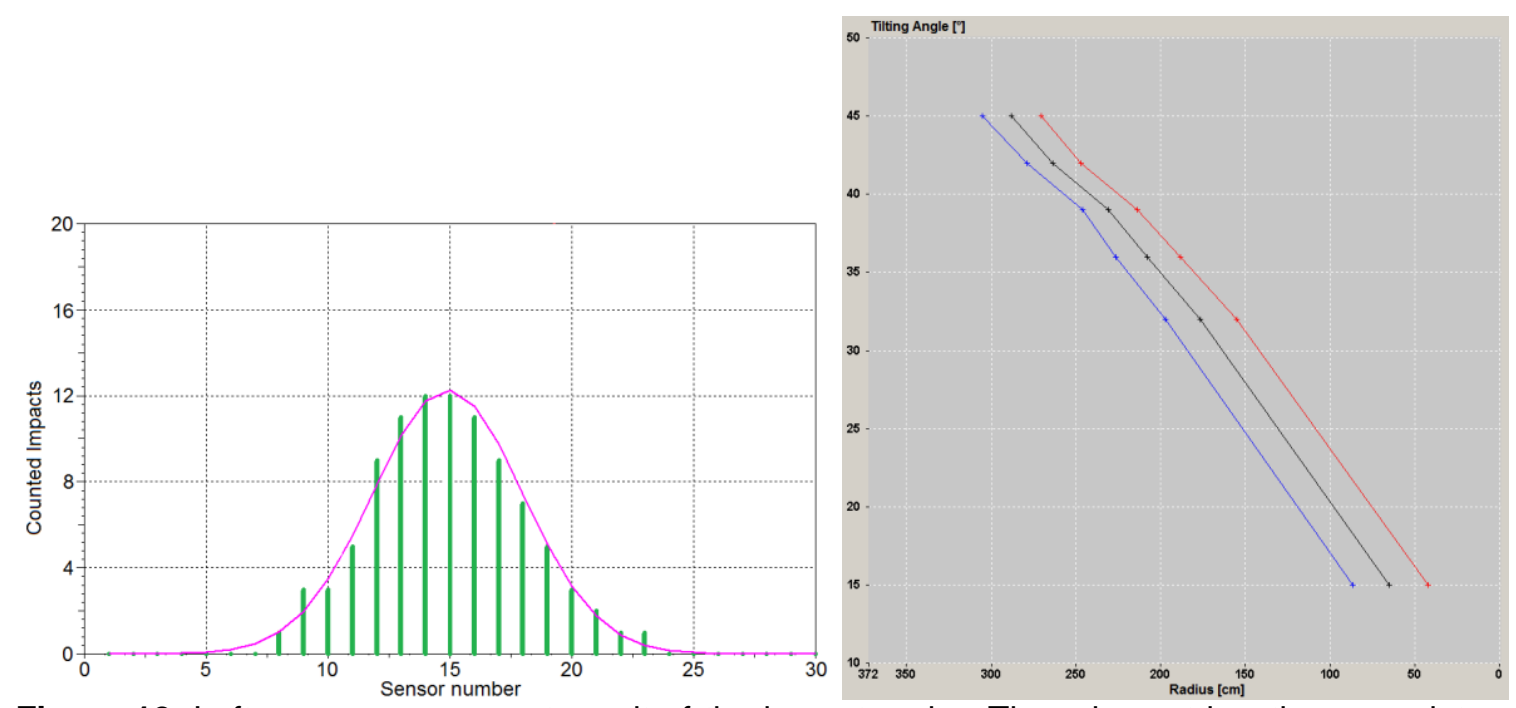

Figure 12. Left: raw measurement result of the impact probe. Three impact locations are determined (outer, central and inner location of material stream) for a known rotating chute tilting angle. Right: With the final result, the operators can associate a desired ring position to an adequate tilting angle.

\subsection{Scanning Probe: SP}

The Scanning Probe is a movable probe installed deep below the burden surface, equipped with a material sensor at the probe tip. The probe is inserted and retracted through the burden over the full radius of the blast furnace, during operation, detecting the coke and ore layers. A predefined number of strokes (i.e., 35) is carried out subsequently. With the combination of the fast horizontal probe movement $(<1$ min cycle time), and the slower vertical burden descent $(10-15 \mathrm{~cm} / \mathrm{min})$, a "scan" of the material layers inside the burden is obtained.

Again, no electronic components are installed within the probe, as it is exposed to high loads and heat inside the burden. As the probe remains in the blast furnace during a relatively short time, the static load on the lance remains reasonable, resulting in a very compact size of this probe. The sensor technology is further described in [4].

The Scanning Probe is an in-burden measurement and provides the real burden distribution in the blast furnace shaft. The measurement results include the effects of: the strong impact forces during charging, leading to coke pushing or material rolling;

\footnotetext{
* Technical contribution to the 44 Ironmaking and Raw Materials Seminar, $15^{\text {rd }}$ Brazilian Symposium on Iron Ore and $2^{\text {nd }}$ Brazilian Symposium on Agglomeration of Iron Ore, September $15^{\text {th }}$ to $18^{\text {th }}$, 2014, Belo Horizonte, MG, Brazil.
} 
of particle percolation and material mixing; and of coke fluidization on the ore layers in the center. It therefore contains additional information compared to the profilemeter layer model or the fully offline charging model, and completes the understanding of the charging process.

Furthermore, the real burden distribution, expressed as the $\mathrm{C} /(\mathrm{C}+\mathrm{O})$-ratio, is a major input to blast furnace process research models $[2,6]$.
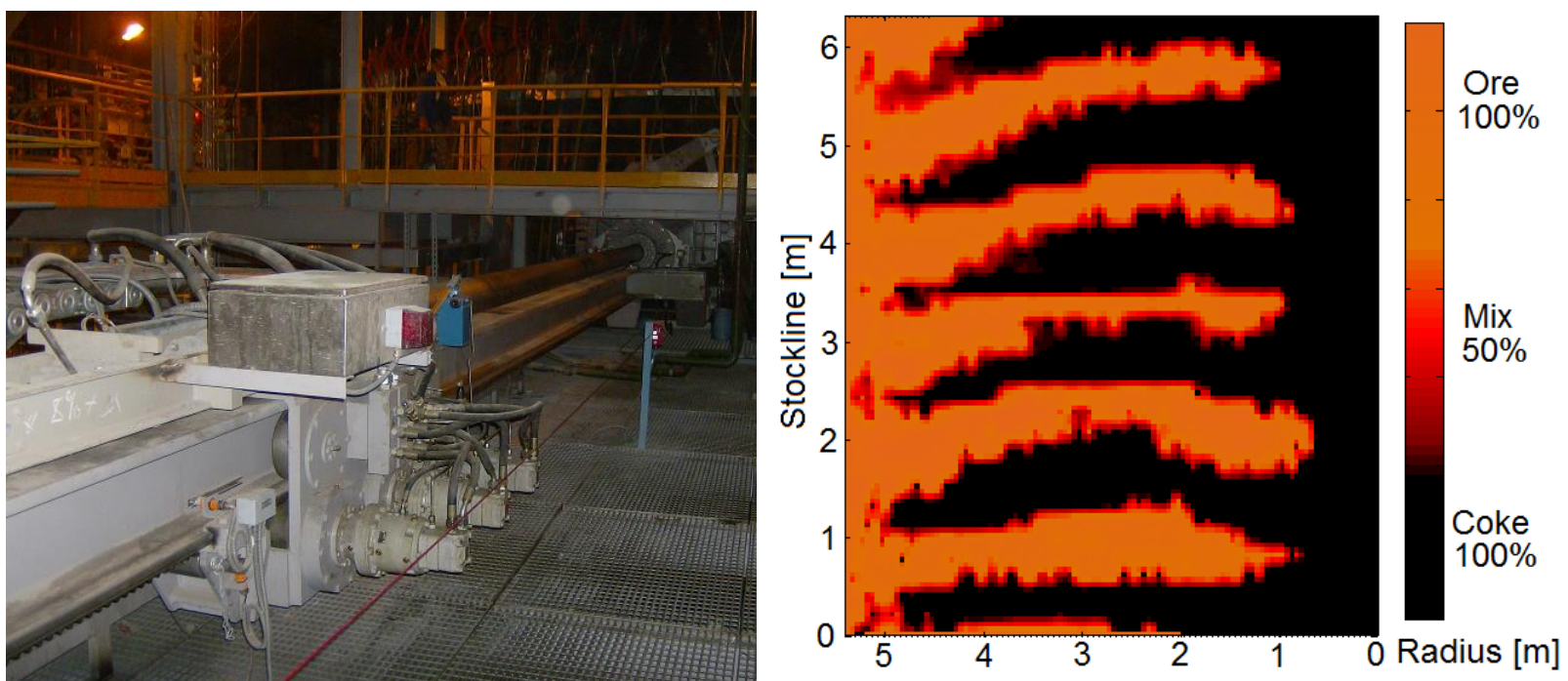

Figure 13. Left: Scanning Probe on a blast furnace. Right: Measurement result showing the real burden distribution in the blast furnace.

\subsection{In-Burden Gas Sampling Probe: BP}

The in-burden probe is a movable probe installed below the burden surface, equipped with a gas sampling system, a gas cleaning and drying stage, and a gas analyzer. During operation of the blast furnace, the probe is positioned at predefined locations below the burden along the blast furnace radius. The process gas is sampled and measured online. The measurement result is the radial distribution of the gas composition and the gas temperature in the shaft.

The gas temperature is measured by a thermocouple installed directly in the front of the lance. For the gas analyzer, the gas is aspired via a high-temperature resistant plug that is only opened at the respective sampling positions.

The process gas is dirty and wet - before it can be measured in the gas analyzer, it has to be cleaned and dried. This is not easy, however, tmt provides such systems since the 70s and thereafter has a large experience. The process gas cleaning and drying stage is fully automated. After the completion of the measurement, also, the probe and the filter equipment is automatically cleaned. For extreme cases, for instance, zinc containing iron ores, injection of heavy oil as fuel, or processing of unsieved coke, additional semi-automatic cleaning systems can be provided.

The cleaned and dried gas is forwarded to an external analyzer. Typically, the concentration of $\mathrm{CO}, \mathrm{CO}_{2}$ and $\mathrm{H}_{2}$ are measured. Additional measurements are possible, for instance, helium or methane. The concentration of remaining gases, foremost of $\mathrm{N}_{2}$, is obtained from stoichiometric calculations.

The radial distribution of the gas composition and the gas temperature in the blast furnace shaft is amongst the most important process measurements [2]. Operators apply them once per shift (i.e., every $8 \mathrm{~h}$ ) to verify the proper gas distribution, and the operation of the reduction process. Compared to an above-burden measurement, the

\footnotetext{
* Technical contribution to the $44^{\text {th }}$ Ironmaking and Raw Materials Seminar, $15^{\text {rd }}$ Brazilian Symposium on Iron Ore and $2^{\text {nd }}$ Brazilian Symposium on Agglomeration of Iron Ore, September $15^{\text {th }}$ to $18^{\text {th }}$, 2014, Belo Horizonte, MG, Brazil.
} 
in-burden gas distribution contains direct information of the process, considering that the process gases start to mix already approx. $20 \mathrm{~cm}$ below the surface [5]. The inburden gas distribution can further serve as major input to process research models [2].

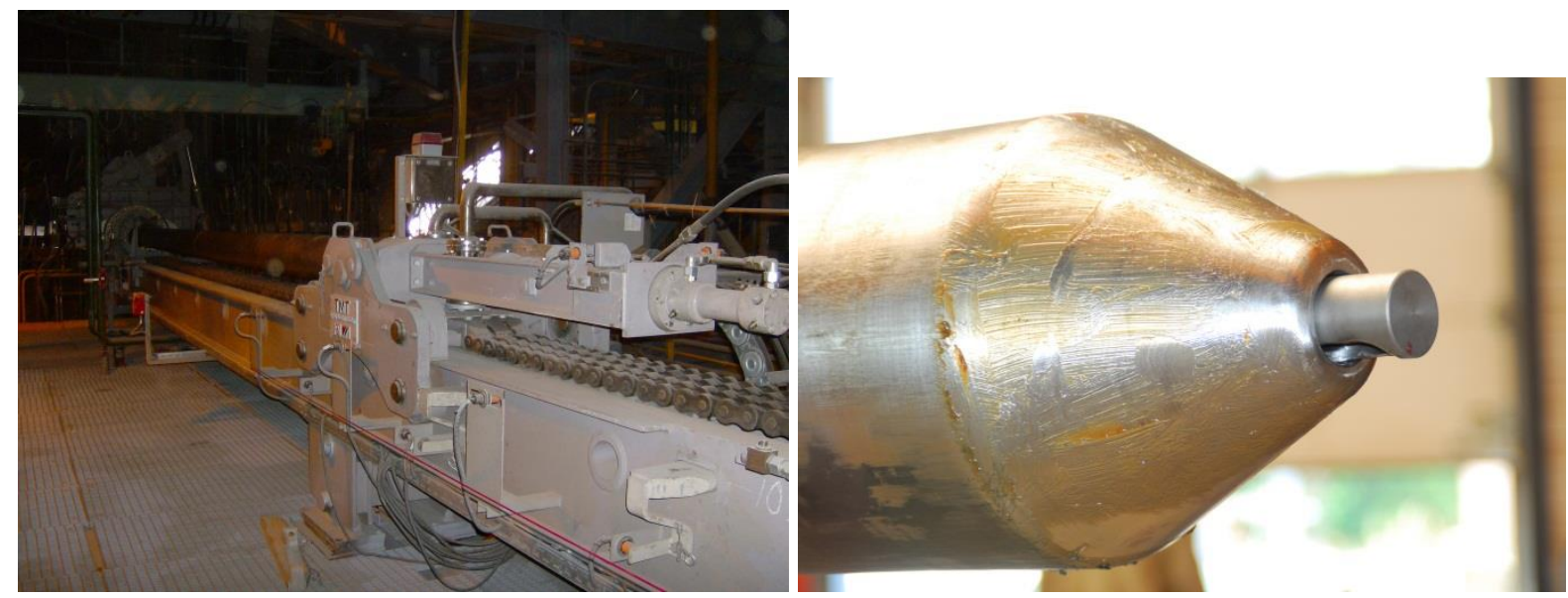

Figure 14. Left: Round BP on a blast furnace. Right: probe head with measurement sampling plug.

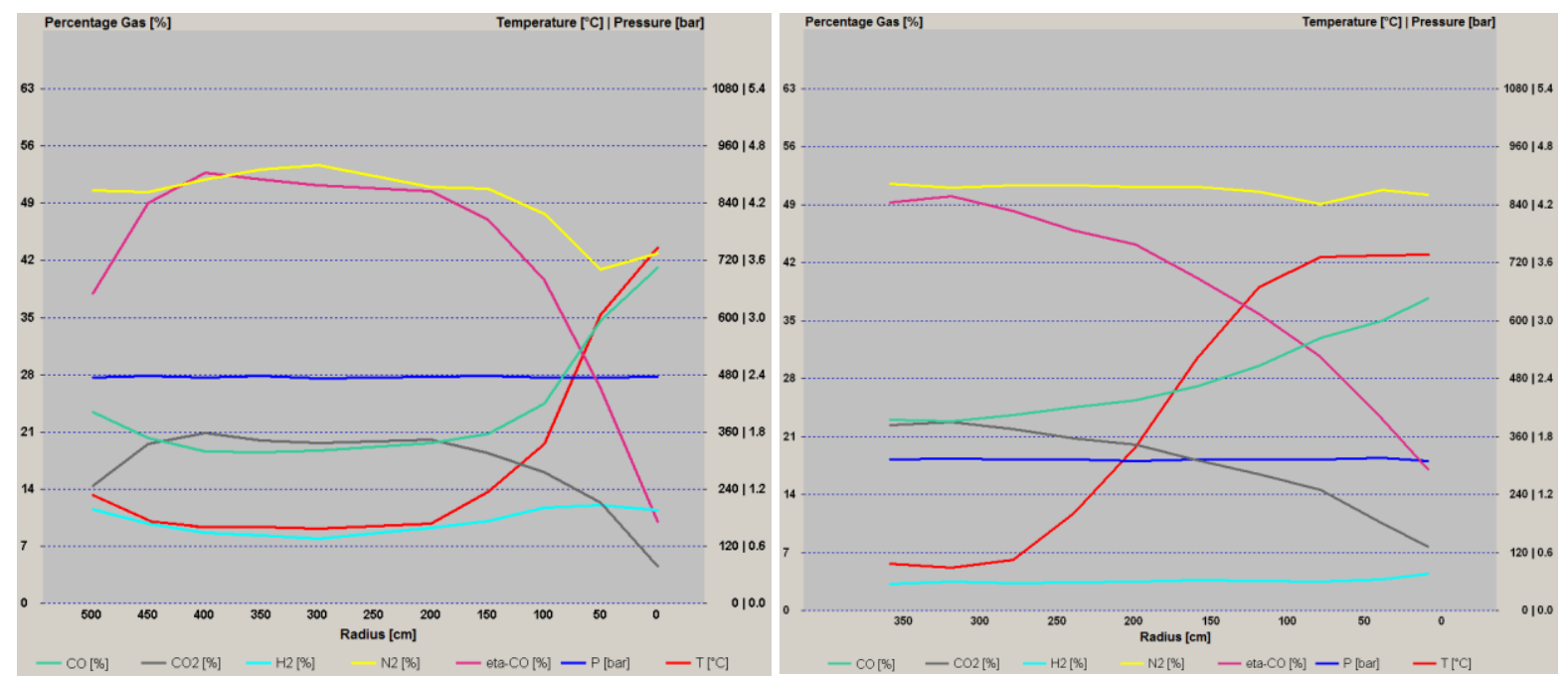

Figure 15. Measurement results of BP. Left: a central-working furnace. Right: a furnace with a widely open central chimney similar to a wall-working furnace. Observe that the main parameters temperature (red line) and eta- $\mathrm{CO}$ (magenta line $\mathrm{CO} 2 /(\mathrm{CO}+\mathrm{CO} 2))$ are not directly inverse related.

\subsection{Above-Burden Gas Sampling and Temperature Probe: ABGT}

An above-burden gas probe is a watercooled beam, installed in a fixed position above the burden. It is fitted with a number of thermocouples to measure the temperature, and a number of gas sampling tubes. It can therefore provide a continuous top gas temperature measurement and a relatively frequent top gas composition sampling. The gas sampling and analyzing sequence is fully automated, together with the subsequent probe cleaning procedure.

\footnotetext{
* Technical contribution to the 44 Ironmaking and Raw Materials Seminar, $15^{\text {rd }}$ Brazilian Symposium on Iron Ore and $2^{\text {nd }}$ Brazilian Symposium on Agglomeration of Iron Ore, September $15^{\text {th }}$ to $18^{\text {th }}$, 2014, Belo Horizonte, MG, Brazil.
} 

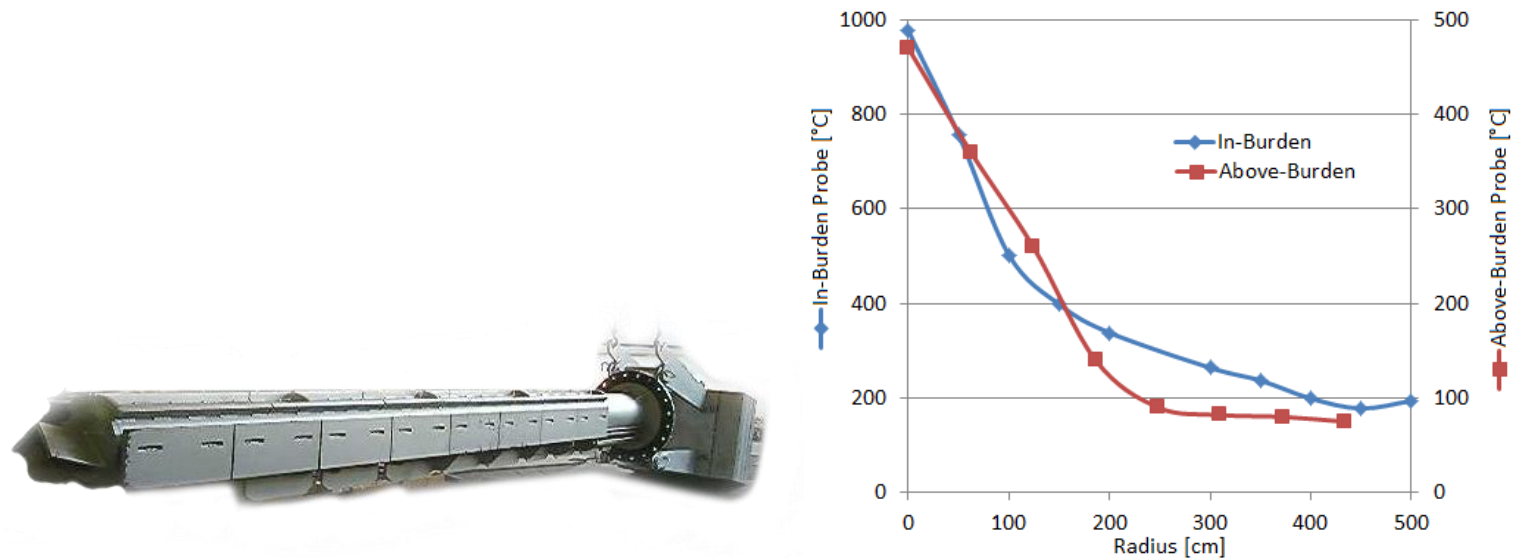

Figure 16: TMT Above-Burden Gas and Temperature Probe. Left: Construction of the watercooled probe with stone boxes on top and a blast furnace center water injection system at the tip. Right: Measurement results of the continuously available temperature distribution compared to an in-burden probe result.

\section{RECOMMENDATIONS FOR BLAST FURNACE EQUIPMENT}

Table 1. Recommendation catalog of probe equipment for blast furnaces

\begin{tabular}{|c|c|c|c|c|c|}
\hline \multirow[b]{2}{*}{ Probe Name } & \multirow[b]{2}{*}{ Code } & \multicolumn{2}{|c|}{$\begin{array}{l}\text { Small to Medium BF } \\
8-13.1 \mathrm{~m} \text { hearth } \varnothing\end{array}$} & \multicolumn{2}{|c|}{$\begin{array}{c}\text { Large BF } \\
>13.1 \mathrm{~m} \text { hearth } \varnothing\end{array}$} \\
\hline & & Basic & Performance & Basic & Performance \\
\hline Stockline Radar & SLR & $\mathrm{X}$ & $\mathrm{X}$ & $\mathrm{X}$ & $\mathrm{X}$ \\
\hline Stockline Mechanical & SLM & $\mathrm{X}$ & $\mathrm{X}$ & $\mathrm{X}$ & $\mathrm{X}$ \\
\hline Furnoscope & FS & & opt. & & opt. \\
\hline Sonic Mapping & SOMA & $\mathrm{X}$ & $\mathrm{X}$ & $\mathrm{X}$ & $\mathrm{X}$ \\
\hline Profilemeter & PM & $x$ & $\mathrm{X}$ & $\mathrm{X}$ & $\mathrm{X}$ \\
\hline Impact Probe & IP & & $\mathrm{X}$ & & $\mathrm{X}$ \\
\hline Scanning Probe & SP & & opt. & & opt. \\
\hline $\begin{array}{l}\text { Above-Burden Gas } \\
\text { Probe- }\end{array}$ & ABGT & & & $x$ & \\
\hline In-Burden Probe & IBP & & $\mathrm{X}$ & & $\mathrm{x}$ \\
\hline
\end{tabular}

Legend: $\mathrm{X}=$ recommended equipment, opt $=$ optional equipment

The equipment proposal, developed together with ironmaking experts, varies with the size of the blast furnace and with the expected performance level. Economic constraints have been taken into consideration, leading to technical limitations, foremost in the 'Basic' configuration. Observe that for a 'Basic' set of equipment, in general, only one movable lance would be installed. Preference is given to the Profilemeter since it is a proven tool for burden distribution control and for assessment of process stability.

It can be seen that above-burden probes disappear from the equipment recommendation. Indeed, an above-burden temperature probe can be considered out-of-date since the availability of the TMT SOMA ${ }^{\mathrm{TM}}$ system. This is supported by the maintenance advantage, by the additional process information, and by the fact that an above-burden probe disturbs the charging.

* Technical contribution to the 44 Ironmaking and Raw Materials Seminar, $15^{\text {td }}$ Brazilian Symposium on Iron Ore and $2^{\text {nd }}$ Brazilian Symposium on Agglomeration of Iron Ore, September $15^{\text {th }}$ to $18^{\text {th }}$, 2014, Belo Horizonte, MG, Brazil. 
For a well-reasoned recommendation, however, the operators experience and preferences have to be considered. For instance, still today, the below-burden gas measurement remains a common method to operate and supervise a blast furnace, and is suitable for everyday use as well as for research purposes. The choices for the 'Basic' configuration have to be considered as a tradeoff between process performance and investment costs.

\section{REFERENCES}

1 Geerdes M, Toxopeus H, Vliet C, Modern Blast Furnace Ironmaking: An Introduction, ISBN 978-1-60750-040-7, IOS Press, Amsterdam, 2009.

2 Omori Y. Blast Furnace Phenomena and Modelling, ISBN 1-85166-057-7, Elsevier Applied Science Publishers, Essex, 1987.

3 Tonteling M, Brodeck M, H. Rausch, 2D Blast Furnace Top Gas Temperature Measurement System - TMT SOMA ${ }^{\mathrm{TM}}$, AISTech Iron and Steel Technology, p 45-55, 2013.

4 Buchwalder J, Hunger J, Klöppel M, Dobroskok VA, Dango R, Kreuz HO. Application of the Automatic Scanning System for Detection of the Real Coke Distribution at BF 5A of EKO Stahl, Germany, Europ. Coke \& Ironmaking Congress, Paris, 2000.

5 Timmer R, Quantitative Description of the Gas Flow Pattern in the Blast Furnace Throat Area, ISBN 92-828-1110-7, European Commission technical steel research, Luxembourg, 1997.

6 Danloy G, Mignon J, Munnix R, Dauwels G, Bonte L. A Blast Furnace Model to Optimize the Burden Distribution, Proc. 60th Ironmaking Conf., 2001.

7 Park JI, Jung HJ, M.K. Jo1, H.S. Oh, and J.W. Han, Mathematical Modeling of the Burden Distribution in the Blast Furnace Shaft, Met. Mater. Int., 2011; 173: 485-496, 2011.

8 Takatan K, Inada T, Ujisawa Y. Three dimensional Dynamic Simulator for Blast Furnace, ISIJ Int., 1999, 39(1):15-22.

9 M. Ichida, K. Anan, M. Takao, K. Kakiuchi, Y. Morizane, I. Yamada, T. Nakayama, Inner Profile and Burden Descent Behavior in the Blast Furnace, Nippon Steel Technical Report, No. 94, pp. 80-86, 2006.

10 Lecacheux B, et al. Characterization of Blast Furnace Operation by means of MultiPoints Vertical Probing Technology, 6th European Coke and Ironmaking Congress, 2011.

* Technical contribution to the 44 Ironmaking and Raw Materials Seminar, $15^{\text {rd }}$ Brazilian Symposium on Iron Ore and $2^{\text {nd }}$ Brazilian Symposium on Agglomeration of Iron Ore, September $15^{\text {th }}$ to $18^{\text {th }}$, 2014, Belo Horizonte, MG, Brazil. 